\title{
PERLINDUNGAN HUKUM MASYARAKAT KOTA PALANGKA RAYA AKIBAT DARI PEMBAKARAN HUTAN DAN LAHAN
}

\author{
SANAWIAH \\ Dosen Program Studi Al-Ahwal Al-Syakshyiyyah Fakultas Agama Islam \\ Universitas Muhammadiyah Palangkaraya
}

\begin{abstract}
The purpose of this study is to determine the cause of land and forest fire protection of the law and to find out on the community a result of land forest fire.

The result of this research; paradigm human thinking today thought that nature and living environment is abundant treasures provided the optimal for the interests of human prosperity, so that nature with its entire contents and explored beyond the limits of exploitation and to disregard the maintened and the sustainability of the environment and destructive natural resources it self. As a result occurs in various environment damage resulting from forest fires and land has to the pont that very worrying.

The absence of legal protection for the community resulting from forest fires and land and still loitering the incendiary land and forest.
\end{abstract}

Keywords : burning, forest and land

\section{ABSTRAK}

Tujuan Penelitian ini adalah untuk mengetahui penyebab kebakaran hutan dan lahan, dan untuk mengetahui perlindungan hukum terhadap masyarakat akibat dari kebakaran hutan dan lahan.

Hasil dari penelitian ini; Paradigma pemikiran manusia dewasa ini yang menganggap bahwa alam dan lingkungan hidup adalah harta berlimpah yang disediakan sebesar-besarnya untuk kepentingan kemakmuran umat manusia, sehingga alam dengan seluruh isinya dieksplorasi dan dan ekploitasi melampaui batas dan mengabaikan aspek keterpeliharaan dan keberlanjutan lingkungan dan merusak sumber daya alam itu sendiri. Akibatnya terjadi berbagai kerusakan lingkungan akibat dari kebakaran hutan dan lahan yang sudah sampai pada titik yang sangat mengkhawatirkan.

Belum adanya perlindungan hukum bagi masyarakat akibat dari kebakaran hutan dan lahan dan masih berkeliarannya para pembakar hutan dan lahan.

Kata kunci: pembakaran, hutan dan lahan

\section{PENDAHULUAN}

Kepentingan Nasional adalah suatu citacita, sasaran yang bersifat umum dan abadi yang digunakan sebagai landasan suatu bangsa untuk bertindak. Dalam kaitan dengan hukum kehutanan dan Hukum Lingkungan maka kepentingan nasional tercantum dalam pasal 33 ayat (2) dan ayat (3) Undang-Undang Dasar 1945, yakni :

(2). Cabang-cabang produksi yang penting bagi Negara dan menguasai hajat hidup orang banyak dikuasai oleh Negara.
(3). Bumi, air dan kekayaan alam yang terkandung didalamnya dikuasai oleh Negara dan dipergunakan untuk sebesar-besarnya kemakmuran rakyat.

Untuk sebesar-besarnya kemakmuran rakyat dalam pengelolaan cabang-cabang produksi, bumi, air dan kekayaan alam oleh Negara maka diperlukan strategi pengelolaan lingkungan tersebut agar tidak memberikan dampak terjadinya kerusakan dan pencemaran lingkungan hidup sehingga kelestarian lingkungan 
hidup tetap terjadi untuk kepentingan generasi saat ini dan masa depan.[UUD 1945]

Sudah lewat sepekan hampir 1 bulan terakhir ini, Provinsi Kalimantan Tengah khususnya Kota Palangka Raya dan Indonesia pada umumnya, terutama Sumatera dan Kalimantan sedang mengalami musibah, yakni kabut asap akibat terjadinya pembakaran hutan dan lahan. Sebagai umat Islam, hal ini di samping sebagai musibah, juga bermakna peringatan yang datang dari Allah SWT kepada umat manusia. Kerusakan di muka bumi sesungguhnya tidak lain adalah ulah perbuatan manusia, yang pada akhirnya akan dirasakan akibatnya oleh manusia sendiri. Musibah banjir atau kabut asap yang sekarang masih menyelimuti Kota Palangka Raya, secara ilmiah disebabkan oleh perbuatan manusia, yakni membakar hutan dan lahan.Undang-undang lingkungan, peraturan Daerah (PERDA) sudah mengatur tentang larangan membakar hutan dan lahan, serta sanksi.Pengelola lahan yang lalai atau yang sengaja melakukan pembakaran akan dikenakan sanksi hukum sesuai dengan perundangundangan yang berlaku, yaitu:

1. Undang-undang Nomor 23 Tahun 1997 tentang Pengelolaan Lingkungan Hidup menjadi Undang-undang Ri Nomor 32 Tahun 2019 dan peraturan Menteri Lingkungan Hudup RI Tahun 2013 tentang Perlindungan dan Pengelolaan Lingkungan Hidup.

2. Undang-undang Nomor 41 Tahun 1999 tentang Kehutanan dan Undang-undang Nomor 18 Tahun 2013 tentang Pencegahan dan Pemberantasan Perusakan Hutan

3. Undang-undang Nomor 18 Tahun 2004 tentang Perkebunan
4. Peraturan Pemerintah Nomor 4 Tahun 2001 tentang Pengendalian Kerusakan dan Pencemaran Lingkungan Hidup yang berkaitan dengan Kebakaran Hutan dan Lahan.

Keterangan diatas sesuai dengan ayat Allah SWT dalam Surat Ar Rum [30] ayat 41- 42 Artinya :

"telah nampak kerusakan di darat dan di laut disebabkan karena perbuatan tangan manusi, supay Allah merasakan kepada mereka sebahagian dari (akibat) perbuatan mereka, agar mereka kembali (ke jalan yang benar).

Katakanlah: "Adakanlah perjalanan di muka bumi dan perhatikanlah bagaimana kesudahan orang-orang yang terdahulu. kebanyakan dari mereka itu adalah orangorang yang mempersekutukan (Allah)."

Al'Quran pun sudah 1400 tahun yang lalu sudah menyampaikan peringatan Sesuai dengan ayat Allah SWT dalam Surah Al A'raf [7] Ayat 5658 tentang Peduli Lingkungan, yang Artinya :

"Dan janganlah kamu berbuat kerusakan di muka bumi sesudah(Allah) memperbaikinya dan berdoalah kepadanya rasa takut (tidak akan diterima) dan harapan (akan dikabulkan). Sesungguhnya rahmat Allah amat dekat kepada orang-orang yang berbuat baik. Dan dialah yang meniupkan angin sebagai pembawa berita gembira sebelum kedatangan rahmaNya (hujan) hingga apabila angin itu telah membawa awan mendung, kami halau kesuatu daerah yang tandus, lalu kami turunkan hujan di daerah itu. Maka kami keluarkan dengan sebab hujan itu berbagai macam buahbuahan. Seperti itulah kami membangkitkan orang-orang yang telah mati, mudahmudahan kamu mengambil pelajaran. Dan tanah yang baik, tanam-tanamannya tumbuh dengan seizin Allah, dan tanah yang tidak subur, tanaman-tanamannya hanya tumbuh merana. Demikianlah kami mengulangi tanda-tanda kebesaran (Kami) bagi orang-orang yang bersyukur" 
Setiap tahun kalimantan Tengah Khususnya Kota Palangka Raya kebakaran hutan dan lahan masyarakat yang mengakibatkan kerusakan, kerugian lingkungan baik tumbuhtumbuhan, hewan bahkan manusia, masyarakat banyak yang sakit Ispa, bahkan meninggal akibat asap, sekolah-sekolah di liburkan karena kabut asap

\section{METODOLOGI}

Metode penelitian yang digunakan adalah metode yuridis normatif mengigat bahwa penelitian ini menekankan bahwa pada data sekunder yakni mempelajari dan mengkaji azasazas, bahan-bahan dan kaidah-kaidah hukum positifnya yang dari bahan-bahan kepustakaan yang ada dalam perundang-undangan kehutanan dan Lingkungan.

Penelitian ini dilakukan dan ditujukan untuk mendapat sisi teoritis maupun doktrin-doktrin hukum dengan mengandalkan bahan-bahan dari buku-buku literatur peraturan perundangundangan, majalah dan surat kabar yang mempunyai relevansi serta memberikan gambaran yang jelas tentang masalah yang akan dibahas, dalam bentuk data sekunder berupa:

a. Bahan Hukum Primer, terdiri dari peraturan perundang-undangan yang berkaitan dengan masalah yang diteliti, diantaranya:

1) Undang-Undang Dasar 1945

2) Undang-undang Nomor 23 Tahun 1997 tentang Pengelolaan Lingkungan Hidup menjadi Undang-undang Ri Nomor 32 Tahun 2019 dan peraturan Menteri Lingkungan Hidup RI Tahun 2013 tentang Perlindungan dan Pengelolaan Lingkungan Hidup.
3) Undang-undang Nomor 41 Tahun 1999 tentang Kehutanan dan Undang-undang Nomor 18 Tahun 2013 tentang Pencegahan dan Pemberantasan Perusakan Hutan

4) Undang-undang Nomor 18 Tahun 2004 tentang Perkebunan

5) Peraturan Pemerintah Nomor 4 Tahun 2001 tentang Pengendalian Kerusakan dan Pencemaran Lingkungan Hidup yang berkaitan dengan Kebakaran Hutan dan Lahan

b. Bahan Hukum Sekunder, berupa tulisantulisan ilmiah dari para pakar yang memberikan penjelasan mengenai bahan hukum primer seperti hasil-hasil penelitian, karya tulis dari kalangan hukum.

c. Bahan Hukum Tersier atau bahan hukum penunjang, mencakup bahan-bahan yang memberi petunjuk-petunjuk maupun penjelasan terhadap hukum primer, hukum sekunder, dan artikel-artikel pada surat kabar.

\section{PEMBAHASAN}

\section{Penyebab Kebakaran Hutan dan Lahan di Kota Palangka Raya}

Pengembangan usaha perkebunan terutama perkebunan kelapa sawit merupakan faktor penting dalam konversi hutan yang berpengaruh pada kebakaran.Kebakaran lahan dan kebun, baik yang merupakan milik masyarakat maupun milik perusahaan perkebunan selalu terjadi pada setiap tahunnya sehingga menimbulkan banyak kerugian dan berdampak pada berbagai aspek kehidupan. 
Aspek ekologis : seperti yang ditandai dengan hilangnya keanekaragaman hayati.Aspek ekonomi : seperti hilangnya tanaman perkebunan dan terganggunya pertumbuhan tanaman pertanian. Aspek sosial yang ditandai dengan munculnya gangguan kesehatan serta dengan munculnya gangguan kesehatan serta terganggunya sarana transportasi.Kebakaran lahan dan kebun selain dapat di pengaruhi oleh iklim, juga dapat disebabkan oleh perbuatan manusia baik secara disengaja maupun karena kelalaiannya. Oleh karena itu, pengusaha dan masyarakat sebagai pengelola lahan, harus bertanggung jawab terhadap akibat ditimbulkannya kebakaran, terutama terhadap upaya pencegahan dan penanggulangannya. [Copyright Dinas Kehutanan dan Perkebunan]

\section{Kebakaran Lahan Disengaja}

Ada 4 titik api di jalan Yos Sudarso, Nyaris Membakar Rumah Warga pada tanggal 07 Agustus 2015 siang, sedikitnya ada 4 titik api membakar semak belukar bergambut di daerah pinggiran Kota Palangka Raya itu. Bahkan kobaran api sampat merambat dengan cepat menuju pemukiman warga. Hampir saja merambat ke rumah penduduk yang ada di sekitarnya. Warga sekitar berusaha memadamkan api dengan peralatan seadanya.[lihat Kalteng Pos sabtu, 8 Agustus 2015] Menurut laporan warga ada yang sengaja membakar api tiba-tiba muncul begitu saja. Petugas dari Badan Pengangulangan Bencana Daerah (BPBD) tiba di lokasi setelah kobaran api meluas. truk Tanhki bermuatan 5.000 Liter air itu akhirnya tiba setelah api menjalar lebih luas dan berhasil memadamkan titik api lainya. Termasuk yang hampir merambat ke rumah warga. Herie Saksono, Asisten I Bagian Pemerintahan Kota Palangka Raya yang juga melihat lokasi kebakaran membantah jika disebutkan bahwa petugas terlambat datang kelokasi kebakaran, Dia menyatakan, Pemko Palangka Raya selalu responsef terhadap laporan warga apabila terjadi kebakaran lahan dan hutan.

\section{Polisi Sulit Tangkap Pembakar Lahan}

Tidak di pungkiri, setiap hari, kebakaran lahan selalu ditemukan di Kota Palangka Raya. Sampai saat ini, penegak hukum belum berhasil menangkap para pelaku pembakar lahan. Kebakaran lahan juga terjdi di Koawaringin Timur sudah sangat menggangu langkah cepat untuk segra mengatasinya. Aparat kepolisian setulnya bisa segera turun tangan menangkap maupun menindak para pelakunya, tapi sampain saat ini belum ada satupun pelaku pembakar yang ditindak maupun diproses, sesuai dengan aturan yang berlaku. [lihat Kalteng Pos 13 Agustus 2015]

Kapolres Kotim AKBP Hendra Wirawan melalui Kabag Ops Kompol Bambang mengatakan polisi sejauh ini sudah melakukan antisisipasi seperti memasang baliho maupun spanduk di lokasi yang dianggap sering terjadi kebakaran lahan. Tetapi memang belum ada tindakan secara represif untuk menindak para pelaku pembakar lahan yang memang ditemukan secara sengaja membakar lahan. 


\section{Bagaimana Perlindungan Hukum Terhadap Masyarakat Akibat dari Kebakaran Hutan dan Lahan}

\section{Kebakaran Lahan Kalteng Dijadikan Ajang Bisnis}

Upaya yang dilakukan pemerintah saat ini untuk menaggulangi bencana kebakaran lahan dan kabut asap dinilai tidak efektif. Peneliti tanah gambut Dr. Suwido H Limin menyebutkan, bencana ini justru terlihat ajang bisnis, dikatakannya pemadaman dengan pesawat dan helikopter itu terlalu mahal dan tidak efektif ," kata Dr. Suwido H Limin Kepada Kalteng Pos, Senin 10 Agustus 2015. Apabila jika dihitung dengan kamov (helikopter) maka pemerintah membeli 1 liter air seharga Rp. 1.111. maka biaya yang dikeluarkan untuk memadamkan lahan yang terbakar seluas 1 hektare berkisar Rp. 2.2-4,2 Miliar. Dikatakannya, berdasarkan hasil penelitiannya untuk memadamkan 1 meter kubik lahan gambut yang terbakar dibutuhkan sekitar 200 liter air. BPBD menyewa 2 unit kamov berdasarka jam pakai sekitar Rp 20 miliar perbulan. Jika asumsi atau hari bekerja 12 jam dan melakukan 5 kali sorti dimana sekali sorti mengangkut 5000 liter air. Maka biaya untuk pemadaman seluas 1 hektare dibutuhkan sekitar Rp. 2.2-4,2 miliar.

Terlebih menurutnya biaya yang lebih mahal lagi jika menggunakan pesawat Beriev BE200 dengan kapasitas 135 ton air, karena untuk sewa 1 jam saja, pemerintah harus mengeluarkan biaya Rp 60 juta atau membayar sekitar Rp. 7.000-8.000 untuk satu liter air. Hasil perhitungannya, jika yang membakar lahan gambut seluas 1 hektare saja maka diperlukan biaya 17-35 miliar untuk pemadaman," angka itu sangat besar dan bisa dimanfaatkan untuk hal lain". Diungkapkan Dr Suwido, dirinya memiliki konsep yang disebut Kalteng Nantilang Asep. Diyakini, dengan konsep ini pemerintah hanya membayar sekitar Rp 40 untuk tiap liter air yang digunakan memadamkan api, konsep ini menurutnya akan di sampaikan kepada presiden, karena konsepnya lebih efektif, mendidik dan membuka lahan pekerjaan. Karena masyarakat bukan menjadi penonton tetapi pelaku penanggulangan kebakaran lahan.[lihat Kalteng Pos 12 Agustus 2015]

\section{Pandangan Islam Dalam Pengelolaan Lingkungan}

Agama Islam adalah agama yang sangat memperhatikan aspek lingkungan, ajaran Islam mengajarkan nilai-nilai yang berkaitan dengan lingkungan ini, dimulai dari kajian yang paling dasar dan mendasar, seperti budaya bersih dan tidak melakukan kerusakan di muka bumi. Manusia sebagai khalifah di muka bumi yang diamanahkan oelh Allah SWT memiliki tugas berat dalam menjaga dan melestarikan alam, meskipun dalam Al-Quran diceritakan bahwa makhluk Allah SWT yang lain, yakni malaikat menyampaikan "protes"nya dengan mengatakan bahwa, untuk apa Allah SWT menciptakan manusia yang diprediksi akan melakukan kerusakan di muka bumi (yufsidu fil ardh) dan melakukan pertumpahan darah (yasfikud dima"), dua prediksi malaikat menyangkut perilaku manusia yang sekarang diyakini sudah terbukti kebenarannya. (lihat QS. Al-Baqarah/2:30)

Di dalam Al-Quran Allah SWT telah memberikan gambaran dan petunjuk yang sangat jelas mengenai alam dan lingkungan yang 
menjadi landasan dasar sikap manusia terhadap alam semesta dan lingkungan; Ayat-ayat yang menyebutkan tentang gambaran alam, tujuan penciptaan alam dan keutamaan-keutamaan serta nikmat-nikmat Allah SWT yang didapatkan oleh manusia melalui alam dan lingkungannya (lihat QS. Al-Nazi"at/79: 23-33, Al-Anbiya/21: 16-18, Ad-Dukhaan/44: 38, Al-Baqarah/2: 22 dan QS. Shaad/38: 27).

Penafsiran ulang atas paradigma itu, bahkan dirasa perlu adanya revolusi spiritual keagamaan dalam menyelamatkan alam dan lingkungan hidup ini, dengan menghadirkan paradigma baru, yakni menambah aspek kecintaan manusia kepada alam (falling in love with world), kemudian menumbuhkan kesadaran bahwa alam dan lingkungan ini adalah titipan anak cucu kita, seribu bahkan sejuta tahun yang akan datang, bukan warisan dari nenek moyang kita, agar kita tidak merusak lingkungan. Dan pada titik akhirnya hendaklah memasukkan nilai spiritual Islam ke dalam pemahaman, kajian serta kebijakan manusia terhadap alam dan lingkungan hidup, tidak melakukan tindakan-tindakan yang akan berakhir pada krisis lingkungan.

Seyyed Houssein Nasr, yang terkenal dengan gagasan a sacred science, menerangkan bahwa berdasarkan pengetahuan profetis Islam, maka Islam menganjurkan penganutnya untuk tidak menaklukkan alam, dalam arti mengeksplorasi sumber daya alam secara brutal, yang berdampak kerusakan parah terhadap lingkungan, dan dampak turunannya seperti banjir dan bencana asap ini. Manusia dapat dan dibolehkan memanfaatkan sumber daya alam sesuai dengan perintah Allah SWT di dalam AlQuran. Oleh karena itu umat Islam harus menanamkan dan mengembangkan nilai-nilai spiritualitas lingkungan dengan mengejawantahkan ajaran-ajaran Al-Quran dan Sunnah Rasulullah SAW tentang pelestarian lingkungan dalam kehidupan sehari-hari.

Islam menekankan bahwa Allah SWT mengajarkan di dalam Al-Quran bahwa manusia sebagai khalifah di muka bumi, tidak hany untuk memikirkan kepentingan dirinya, kelompoknya atau bangsanya saja, tetapi ia juga harus memikirkan kemaslahatan semuanya, termauk alam dan lingkungannya. Menarik untuk diambil kata hikmat seorang spiritualis Islam, Ibn al-"Arabi yang menyebutkan bahwa konsep cinta Tuhan melalui alam, karena melalui alam Tuhan "menampak"kan diri-Nya dan "memperkenalkan" diri-Nya. Sehingga bagi manusia mencintai alam berarti mencintai Tuhan dan apabila mencintai Tuhan harus pula mencintai alam.

\section{KESIMPULAN DAN SARAN}

\section{Kesimpulan}

Paradigma pemikiran manusia dewasa ini yang menganggap bahwa alam dan lingkungan hidup adalah harta berlimpah yang disediakan sebesar-besarnya untuk kepentingan kemakmuran umat manusia, sehingga alam dengan seluruh isinya dieksplorasi dan ekploitasi melampaui batas dan mengabaikan aspek keterpeliharaan dan keberlanjutan lingkungan dan merusak sumber daya alam itu sendiri. Akibatnya terjadi berbagai kerusakan lingkungan yang sudah sampai pada titik yang sangat mengkhawatirkan. 
Belum ada perlindungan hukum bagi masyarakat akibat dari kebakaran hutan dan lahan dan masih berkeliarannya para pembakar hutan dan lahan.

\section{Saran}

Adanya kerjasama pemerintah dengan masyarakat dalam penangulangan kebakaran hutan dan lahan, tindakan pencegahan merupakan komponen terpenting dari seluruh system penanggulangan bencana termasuk kebakaran. Bila pencegahan dilaksanakan dengan baik, seluruh bencana kebakaran dapat diminimalkan atau bahkan dihindarkan. Pencegahan kebakaran diarahkan untuk meminimalkan atau menghilangkan sumber api dilapangan.

Biaya yang besar untuk kegiatan penanggulangan kebakaran namun tidak efektif lebih baik dimanfaatkan untuk kepentingan masyarakat yang terkena dampak kebakaran hutan dan lahan, seperti pengobatan Ispa dan bantuan penenaman kembali kebun masyarakat yang terbakar akibat uknum yang tidak bertanggung jawab.

\section{DAFTAR PUSTAKA}

Ahmad Redi "Hukum Sumber Daya Alam Dalam Sektor Kehutanan" ,Jakarta, Sinar Grafika, 2014.

Bertens "Pengantar Etika Bisnis" Seri Filasafat Atmajaya, Yokyakarta. Kanisius, 2000.

Bentham, Jeremy "An Introduktion to the Principles of Morals and Legislation" Kitchener, Batoche Books, 2000.

Bacow and Wheeler, "Environmental Law Handbook'York, Plennum Press, 1984.
Cremona, Marissa "Criminal Law" London, Mac Millan Education Ltd, 1989.

Internet, Supian Atikel"Pesan Al-quran Mengenai Kerusakan Lingkungan" Jumat, 17/10/2014 - 10:11:07 WIB

Peraturan Pemerintah Nomor 4 Tahun 2001 tentang Pengendalian Kerusakan dan Pencemaran Lingkungan Hidup yang berkaitan dengan Kebakaran Hutan dan Lahan.

Takdir Rahmadi " Hukum Lingkungan di Indonesia" Jakarta PT Raja Grafindo Persada, 2013

Undang-undang Nomor 23 Tahun 1997 tentang Pengelolaan Lingkungan Hidup.

Undang-undang Ri Nomor 32 Tahun 2019 dan peraturan Menteri Lingkungan Hudup RI Tahun 2013 tentang Perlindungan dan Pengelolaan Lingkungan Hidup.

Undang-undang Nomor 41 Tahun 1999 tentang Kehutanan dan Undang-undang Nomor 18 Tahun 2013 tentang Pencegahan dan Pemberantasan Perusakan Hutan.

Undang-undang Nomor 18 Tahun 2004 tentang Perkebunan. 